\title{
PERANCANGAN DAN ANALISIS SISTEM SMART LIGHTING BERBASIS WIRELESS SENSOR NETWORK UNTUK MENINGKATKAN KENYAMANAN AKTIVITAS DI DALAM RUMAH
}

\author{
Fidelis Surya Putranta ${ }^{1}$, Rendy Munadi ${ }^{2}$, Yoseph Gustommy Bisono ${ }^{3}$
}

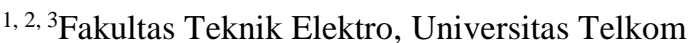

fidelissurya@yahoo.com ${ }^{1}$, rendymunadi@ telkomuniversity.ac.id ${ }^{2}$, bisono@ telkomuniversity.ac.id $^{3}$

\begin{abstract}
Abstrak
Dewasa ini, smart lighting menjadi sebuah teknologi yang layak digunakan untuk menunjang produktivitas. Smart lighting sendiri menggunakan lampu LED yang dipadukan dengan sensor. Sensor merupakan alat yang digunakan untuk mendeteksi adanya perubahan lingkungan fisik atau kimia. Dalam penelitian ini digunakan sensor LDR sebagai pendeteksi tingkat intensitas cahaya di dalam ruangan. Sensor tersebut mendeteksi keadaan cahaya di ruangan dan menyesuaikan dengan tingkat intensitas cahaya yang direkomendasikan, kemudian dilakukan pengiriman informasi ke lampu LED untuk menyala dengan menggunakan sebuah mikrokontroler (Arduino). Pada sistem ini, sensor terhubung dengan jaringan dalam sebuah Wireless Sensor Network. Data dari sensor node dikirimkan ke coordinator node secara nirkabel menggunakan XBee kemudian dikirimkan ke server untuk diolah dan dipantau. Informasi server dapat diakses, dipantau dan dikendalikan menggunakan perangkat mobile maupun komputer dengan akses jaringan internet. Dari hasil pengujian terhadap XBee, semakin jauh jarak sensor node dengan coordinator node maka delay akan semakin besar. Sementara throughput akan semakin kecil, begitu pula sebaliknya. Pada pengujian server, delay pada proses monitoring lebih kecil daripada delay pada proses controlling. Sedangkan throughput monitoring lebih besar daripada throughput controlling. Sistem memiliki reliability sebesar $\mathbf{9 5 , 1 7 \%}$ dan availability sebesar $\mathbf{9 5 , 4 \%}$.
\end{abstract}

Kata Kunci: LED, Arduino, sensor cahaya, XBee

\section{Abstract}

Now, smart lighting become a feasible technology to increase productivity. Smart lighting uses LED and sensor. Sensor is a device that detect any physical or chemical environment changes. This research used LDR sensors as a detector level of light intensity in the room. The sensor detects the state of light in the room and adjusts it to recommended light intensity, then sends the information to the LED to light up using a microcontroller (Arduino). The sensor connected to the network within a wireless sensor network. The data from the sensor node sent to the coordinator node wirelessly using XBee and then sent to the server for processing. All information monitored on a server. The information can be accessed, monitored, and controlled using mobile devices or computers with internet access. From the results of testing on XBee, the more distance the sensor node from the coordinator node, the delay will be greater. On the hand, the throughput will be smaller, and vice versa. In server testing, the delay on the monitoring process is smaller than the delay in the controlling process. While the throughput monitoring is higher than the throughput of controlling. The system has a reliability of $95.17 \%$ and availability of $95.4 \%$.

Keywords: LED, Arduino, light sensor, XBee

\section{Pendahuluan}

Lampu memiliki peran yang sangat penting sebagai sumber penerangan di dalam maupun di luar rumah. Lampu yang sekarang sedang ramai digunakan adalah lampu Light Emitting Diode (LED). Lampu LED memiliki keunggulan yaitu lebih hemat listrik dibandingan dengan lampu konvensional yang masih ada di pasaran. Keunggulan lainnya, lampu LED memiliki cahaya dengan berbagai warna sehingga dapat digunakan untuk berbagai tujuan. Dalam penelitian ini, LED difungsikan untuk mampu memancarkan cahaya dengan intensitas tertentu bergantung dengan tingkat intensitas cahaya dalam ruangan. Ruangan yang memiliki pencahayaan yang baik akan menunjang kenyamanan dalam beraktivitas. Cahaya dari lampu LED tersebut membantu dalam meningkatkan kenyamanan sehingga tetap produktif melakukan aktivitas maupun bersantai di dalam rumah. Smart lighting sebagai teknologi baru menjadi pilihan sebagai penunjang kenyamanan di dalam rumah, smart lighting menggunakan LED dan sensor sebagai elemen utamanya. Smart lighting dihubungkan dengan jaringan internet untuk dapat dimonitor dan dikontrol dari jarak jauh. Tujuannya adalah untuk memberikan kenyamanan kepada pengguna dengan pengaturan intensitas cahaya LED 
yang memancarkan cahaya yang terang sesuai dengan rekomendasi yaitu 250 lux. Tujuan lainnya adalah untuk mengetahui delay, throughput, reliability, dan availability pada jaringan sensor nirkabel ketika smart lighting tersebut beroperasi.

Smart lighting adalah salah satu produk dari Internet of Things (IoT) yaitu perangkat disekitar manusia yang terkoneksi dengan internet dan dapat dikendalikan secara nirkabel. Pengendalian tersebut memerlukan sensor dan jaringan nirkabel atau biasa disebut Wireless Sensor Network(WSN) yaitu suatu jaringan komunikasi sensor yang terhubung secara nirkabel yang terdiri dari beberapa sensor (sensor node) yang diletakkan di tempat-tempat yang berbeda untuk memonitor kondisi suatu sistem [1, 2, 3]

\section{Tinjauan Pustaka}

\subsection{Internet of Things (IoT)}

IoT adalah perangkat disekitar manusia yang terkoneksi dengan internet dan dapat dikendalikan secara nirkabel. IoT menggunakan antarmuka dan terintegrasi ke dalam jaringan informasi serta dapat melakukan komunikasi data kepada pengguna dan lingkungannya $[4,5]$.

\subsection{Wireless Sensor Network (WSN)}

WSN merupakan suatu jaringan komunikasi sensor yang terhubung secara nirkabel yang terdiri dari beberapa sensor (sensor node) yang diletakkan ditempat - tempat yang berbeda untuk memonitoring kondisi suatu sistem [6]. WSN memanfaatkan teknologi embedded system dan seperangkat node sensor, untuk melakukan proses sensing, monitoring, pengiriman data dan penyajian informasi ke pengguna melalui komunikasi di internet $[7,8]$.

\subsection{Smart Lighting}

Smart lighting di dalam rumah membantu dalam menghemat energi dengan mengadaptasikan cahaya ke dalam kondisi yang bermacam-macam dan menjadi saklar on/off atau mengatur intensitas cahaya bila diperlukan. Teknologi kunci dari smart lighting menggunakan perangkat pencahayaan (misalnya cahaya LED), sensor, dan perangkat IP sebagai penyambungnya. Smart lighting untuk rumah membuat hemat energi dengan merasakan pergerakan manusia dan lingkungannya serta mengontrol cahaya sedemikian rupa. Lampu yang terkoneksi internet maupun jaringan nirkabel dapat dikontrol dari jarak jauh dengan aplikasi IoT misalnya, aplikasi smartphone maupun aplikasi web. Smart lighting dengan sensor untuk jumlah lampu, temperatur cahaya, tingkat intensitas cahaya bisa diatur untuk mengadaptasi cahaya (dengan mengganti intensitas cahaya, warna cahaya, dan sebagainya) sesuai kondisi yang dirasakan untuk memperoleh kondisi lingkungan yang baik [4].

\subsection{Kenyamanan Menurut Warna Sinar Lampu}

Kuning meredup memiliki sifat membangkitkan kenyamanan ruang kerja atau ruang belajar. Kuning yang meredup, seperti matahari pada sore hari, menciptakan nuansa penuh kehangatan. Sehingga sangat tepat jika menggunakan sinar lampu kuning yang terang di ruang kerja. Sedangkan sinar putih memberikan kesan yang dingin dan mengisolasi. Hal ini menyebabkan orang-orang di dalam ruang lebih suka bersosialisasi untuk membuat suasana lebih hangat dan nyaman.

\section{Perancangan dan Analisis}

\subsection{Desain Model}

Blok sistem yang dirancang dibagi menjadi empat bagian yaitu perangkat sensor node, coodinator node, server internet, dan interface (web). Sensor node terdiri dari sensor cahaya, Arduino, XBee [9, 10], lampu LED, terhubung ke coodinator node yang terdiri dari XBee dan Raspberry Pi untuk pengambilan data lalu dikirim ke server untuk ditampilkan ke perangkat interface. Pertukaran data tersebut dapat melewati internet atau juga bisa dalam jaringan yang sama antara perangkat interface dengan server.

\subsection{Diagram Alir}

Proses kerja dari perangkat smart lighting yaitu, sensor cahaya membaca intensitas cahaya di luar ruangan, data tersebut dikirim ke mikrokontroler untuk diolah. Kemudian mikrokontroler mengecek waktu pada saat itu, dan disesuaikan dengan intensitas cahaya di luar. Jika cocok, misalnya jam 12 siang sesuai dengan intensitas cahaya yang sebenarnya (kondisi cerah) maka dalam sistem memakai acuan berdasarkan intensitas cahaya kemudian data tersebut dikirim ke mikrokontroler. Jika tidak cocok, misalnya jam 12 siang tetapi tidak sesuai dengan intensitas cahaya diluar (kondisi mendung) maka dalam sistem memakai acuan beradasarkan jam kemudian data tersebut dikirim ke mikrokontroler dan disimpan di server.

Data yang diperoleh, baik berdasarkan intensitas maupun waktu, diolah di mikrokontroler kemudian digunakan untuk menyalakan lampu. Lampu dinyalakan dengan warna nyala yang berbeda bergantung dengan intensitas cahaya maupun jam kerja.

Tabel 1. Jarak Sensor Node ke Coordinator Node di Lantai 2

\begin{tabular}{|c|c|c|}
\hline Nama Kamar & Jarak (m) & Penghalang \\
\hline Sakura & 3 & Tidak ada penghalang \\
\hline Teratai & 3 & 1 tembok \\
\hline Melati & 3 & 1 tembok \\
\hline Mawar & 6 & 2 tembok \\
\hline
\end{tabular}




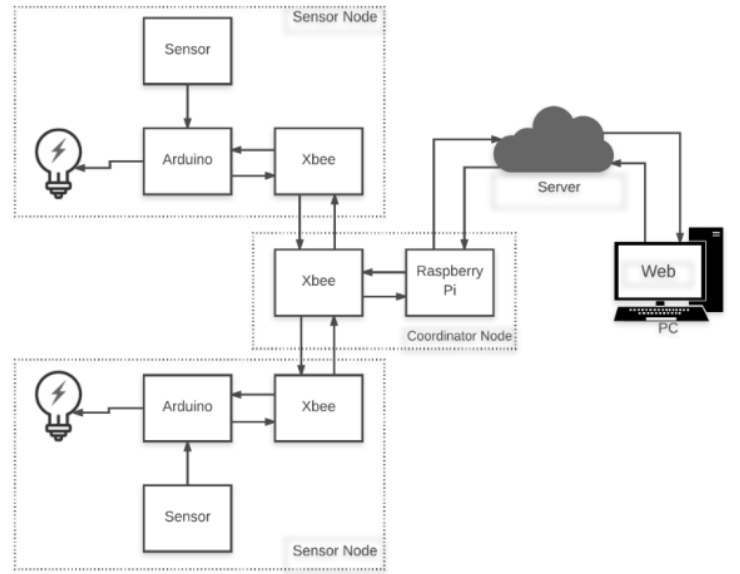

Gambar 1. Desain Model Sistem

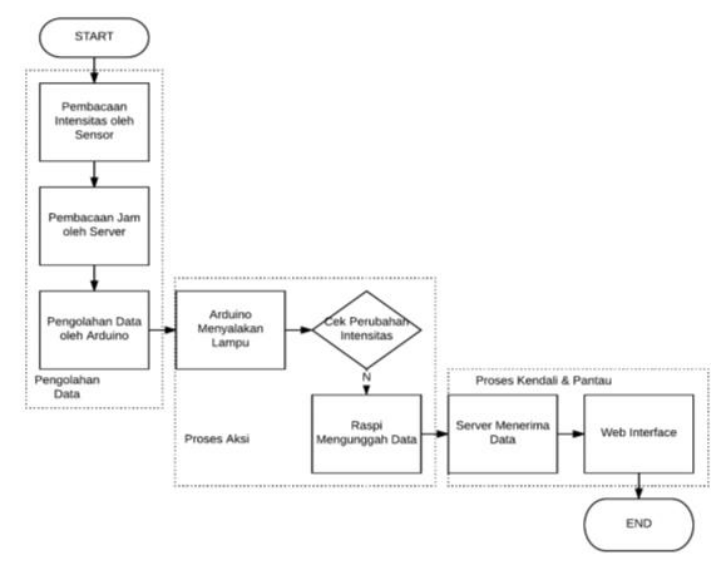

Gambar 2. Diagram Alir Sistem
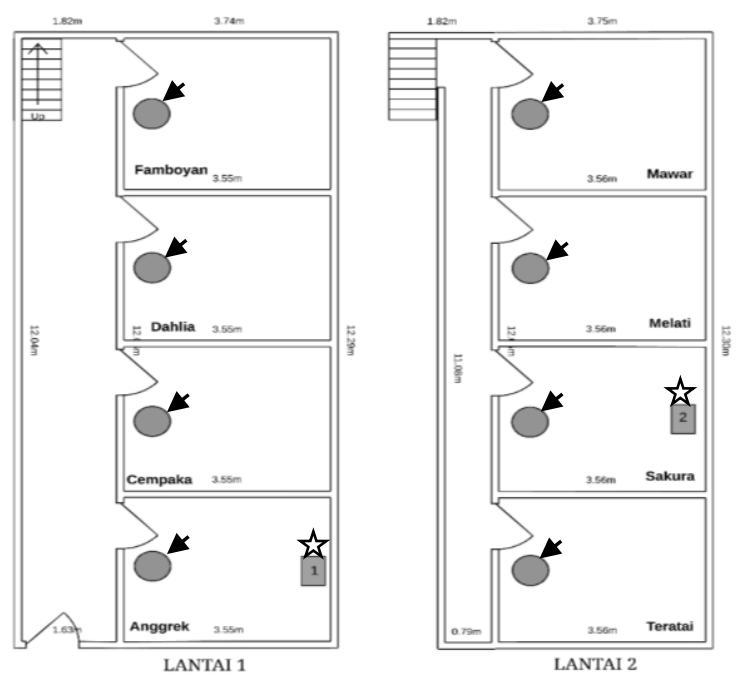

Gambar 3. Denah Pengujian Sistem

\subsection{Analisis Pembacaan Sensor}

Dilakukan pengujian di delapan ruangan berbeda. Sensor node (ditandai dengan panah pada lingkaran) diletakkan pada masing-masing kamar. Coodinator node ada di kamar Sakura di lantai 2 dan kamar Anggrek di lantai 1 (ditandai dengan kotak berbintang). Pada denah tersebut, masing-masing sensor node pada setiap kamar memiliki jarak yang berbeda-beda terhadap coodinator node.
Tabel 2. Jarak Sensor Node ke Coordinator Node di Lantai 1

\begin{tabular}{|c|c|c|}
\hline Nama Kamar & Jarak $(\mathrm{m})$ & Penghalang \\
\hline Anggrek & 3 & Tidak ada penghalang \\
\hline Cempaka & 3 & 1 tembok \\
\hline Dahlia & 6 & 2 tembok \\
\hline Flamboyan & 9 & 3 tembok \\
\hline
\end{tabular}

Tabel 3. Hasil Pembacaan Kondisi oleh Sensor

\begin{tabular}{|c|c|c|c|c|c|c|c|c|c|c|c|}
\hline \multicolumn{2}{|c|}{ Time } & 08.00 & 09.00 & 10.00 & 11.00 & 12.00 & 13.00 & 14.00 & 15.00 & 16.00 & 17.00 \\
\hline \multirow{2}{*}{$\begin{array}{c}\text { Kamar } \\
\text { Anggrek }\end{array}$} & $\begin{array}{c}\text { Light } \\
\text { Intensity }(l u x)\end{array}$ & 224 & 237 & 240 & 254 & 278 & 282 & 226 & 216 & 199 & 183 \\
\hline & LED Intensity & 46 & 33 & 10 & 0 & 0 & 0 & 24 & 44 & 51 & 97 \\
\hline \multirow{2}{*}{$\begin{array}{c}\text { Kamar } \\
\text { Cempaka }\end{array}$} & $\begin{array}{c}\text { Light } \\
\text { Intensity }(l u x)\end{array}$ & 223 & 237 & 243 & 266 & 269 & 276 & 255 & 244 & 209 & 175 \\
\hline & LED Intensity & 27 & 13 & 7 & 0 & 0 & 0 & 0 & 12 & 13 & 12 \\
\hline \multirow{2}{*}{$\begin{array}{l}\text { Kamar } \\
\text { Dahlia }\end{array}$} & $\begin{array}{c}\text { Light } \\
\text { Intensity }(l u x)\end{array}$ & 127 & 139 & 162 & 166 & 174 & 182 & 177 & 170 & 161 & 15. \\
\hline & LED Intensity & 123 & 111 & 88 & 84 & 76 & 68 & 73 & 80 & 89 & 9.5 \\
\hline \multirow{2}{*}{$\begin{array}{l}\text { Kamar } \\
\text { Flamboyan }\end{array}$} & $\begin{array}{c}\text { Light } \\
\text { Intensity }(l u x)\end{array}$ & 102 & 110 & 117 & 122 & 124 & 120 & 118 & 110 & 103 & 92 \\
\hline & LED Intensity & 148 & 140 & 133 & 128 & 126 & 130 & 132 & 140 & 147 & 158 \\
\hline \multirow{2}{*}{$\begin{array}{l}\text { Kamar } \\
\text { Mawar }\end{array}$} & $\begin{array}{c}\text { Light } \\
\text { Intensity }(l u x)\end{array}$ & 193 & 198 & 203 & 211 & 223 & 217 & 210 & 209 & 197 & 191 \\
\hline & LED Intensity & 57 & 52 & 47 & 39 & 27 & 33 & 40 & 41 & 53 & 59 \\
\hline \multirow{2}{*}{$\begin{array}{l}\text { Kamar } \\
\text { Melati }\end{array}$} & $\begin{array}{c}\text { Light } \\
\text { Intensity }(l u x) \\
\end{array}$ & 214 & 228 & 235 & 240 & 246 & 243 & 241 & 238 & 235 & 229 \\
\hline & LED Intensity & 36 & 22 & 15 & 10 & 4 & 7 & 9 & 12 & 15 & 21 \\
\hline \multirow{2}{*}{$\begin{array}{l}\text { Kamar } \\
\text { Sakura }\end{array}$} & $\begin{array}{c}\text { Light } \\
\text { Intensity }(l u x)\end{array}$ & 239 & 242 & 250 & 259 & 264 & 266 & 251 & 247 & 241 & 238 \\
\hline & LED Intensity & 11 & 8 & 0 & 0 & 0 & 0 & 0 & 3 & 9 & 12 \\
\hline \multirow{2}{*}{$\begin{array}{l}\text { Kamar } \\
\text { Teratai }\end{array}$} & $\begin{array}{c}\text { Light } \\
\text { Intensity }(l u x)\end{array}$ & 241 & 245 & 251 & 258 & 262 & 260 & 253 & 248 & 241 & 239 \\
\hline & LED Intensity & 9 & 5 & 0 & 0 & 0 & 0 & 0 & 2 & 9 & 11 \\
\hline
\end{tabular}

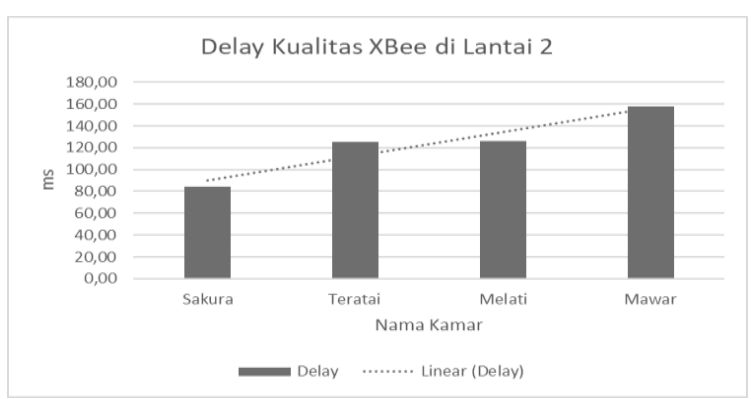

Gambar 4. Delay Kualitas XBee di Lantai 2

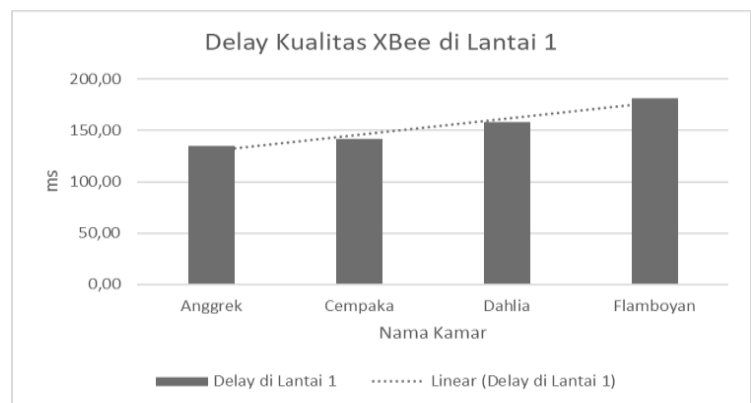

Gambar 5. Delay Kualitas XBee di Lantai 1

Dari Tabel 3 diperoleh nilai intensitas pada kamar Flamboyan dan Dahlia lebih rendah karena kondisi kamar berada di pojok dan memiliki pencahayaan yang kurang, sedangkan kamar Anggrek, Cempaka, Sakura, dan Teratai memiliki intensitas cahaya yang tinggi karena pada kamar tersebut terdapat cahaya matahari langsung yang menerangi kamar tersebut. Pada kamar Mawar dan Melati intensitas cahayanya tidak terlalu tinggi 
maupun rendah karena kamar tersebut mendapat sinar matahari tidak langsung.

\subsection{Analisis Kualitas Jaringan XBee}

\subsubsection{Delay}

Didapatkan rata-rata delay [12, 13] kamar Sakura dengan jarak 3 meter adalah 84,03 milisecond hal ini disebabkan karena sensor node dan coodinator node terletak pada satu ruangan tanpa ada penghalang. Sedangkan pada kamar Teratai dan Melati memiliki nilai delay yang hampir serupa karena jarak antara sensor node dengan coodinator node adalah 3 meter dan kedua kamar tersebut terhalang oleh tembok. Di lantai 1 pada kamar Anggrek dan Cempaka yang memilik jarak 3 meter diperoleh delay 134,57 milisecond untuk kamar Anggrek dan 141,93 milisecond untuk kamar Cempaka, perbedaan hasil diperoleh karena adanya penghalang yang berbeda setiap kamarnya. Pada kamar Mawar diperoleh delay 157,62 milisecond dan Dahlia 158,03 milisecond karena memiliki jarak 6 meter. Pada kamar Flamboyan dengan jarak 9 meter diperoleh delay sebesar 181,28 milisecond

\subsubsection{Throughput}

Diperoleh nilai throughput $[12,13]$ rata-rata untuk kamar Sakura yaitu 16,65 bytes/second dengan nilai yang paling besar, karena delay kamar Sakura paling kecil sehingga pada waktu yang sama, jumlah paket yang dikirimkan bisa lebih banyak.

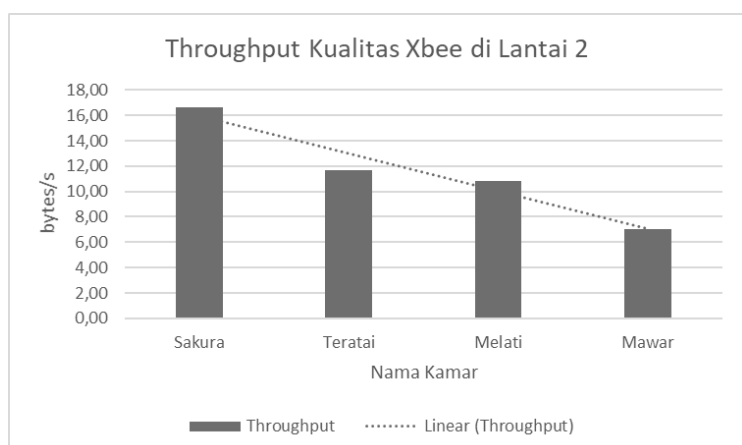

Gambar 6. Throughput Kualitas XBee di Lantai 2

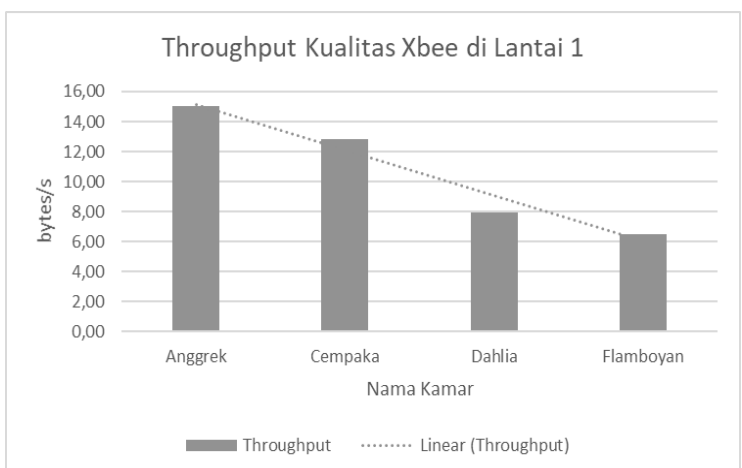

Gambar 7. Throughput Kualitas XBee di Lantai 1
Throughput rata-rata yang paling kecil pada kamar Flamboyan yaitu 6,52 bytes/second karena delay pada kamar Flamboyan lebih besar sehingga pada waktu yang sama paket data yang dikirim menjadi lebih sedikit. Berdasarkan jarak antara sensor node dengan coodinator node, semakin jauh jaraknya maka nilai throughput semakin kecil, karena semakin besar jarak, maka delay semakin besar. Pada selang waktu yang sama delay akan menyebabkan jumlah paket yang diterima menjadi sedikit.

\subsection{Analisis Kualitas Jaringan Server Internet}

\subsubsection{Throughput}

Grafik pada Gambar 8 menunjukkan perbandingan antara throughput $[12,13]$ pada proses monitoring dengan throughput pada proses controlling. Sementara untuk nilai throughput proses controlling lebih rendah daripada proses monitoring karena pada rata-rata timespan (lama waktu pengamatan dari paket dari paket pertama hingga paket terakhir) yang sama, data yang dikirim lebih sedikit sedangkan proses monitoring untuk waktu yang sama data yang dikirimkan lebih banyak sehingga throughput proses monitoring lebih besar.

\subsubsection{Delay}

Pada Gambar 9 dilakukan perbandingan delay $[12,13]$ pada proses monitoring dengan delay pada proses controlling untuk melihat kualitas.

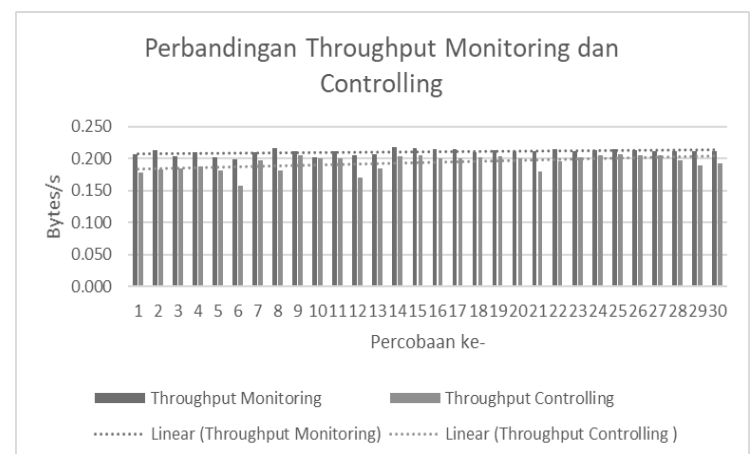

Gambar 8. Perbandingan Throughput Monitoring dengan Controlling

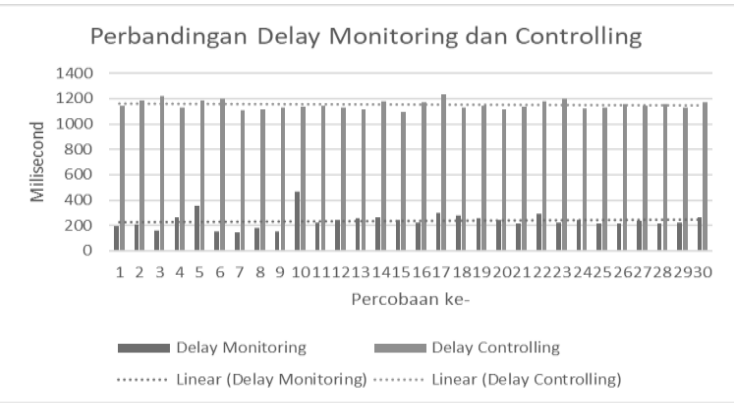

Gambar 9. Perbandingan Delay Monitoring dengan Controlling 
Nilai delay yang didapat dari percobaan di atas, menunjukkan bahwa delay yang lebih kecil pada proses controlling diakibatkan untuk ukuran paket yang sama waktu pengirimannya akan lebih kecil karena paket proses controlling lebih kecil dibandingkan dengan paket pada proses monitoring saat memasuki server. Hasil untuk delay monitoring sudah bagus sebesar 237 milisecond tetapi untuk delay contrrolling masih kurang bagus karena mencapai 1 detik, untuk mengatasi hal tersebut bisa dengan mengurangi delay pada sistem dan delay proses.. Pada Gambar 9, delay pada monitoring ditunjukkan dengan diagram batang yang pendek dan delay pada controlling ditunjukkan dengan diagram batang yang panjang

\subsection{Antarmuka Laman Web}

Pengujian dilakukan dengan membuat laman web pada penyedia layanan server internet DigitalOcean. Penggunaan laman web ini bertujuan untuk menjadi perantara antara pengguna dengan sistem sehingga memudahkan pengguna dalam memantau kondisi smart lighting dengan menampilkan data-data dari smart lighting dan memantaunya dengan mudah dari jarak jauh hanya dengan koneksi internet. Laman web dapat diakses dengan alamat lampupintar.tk dengan tampilan pada Gambar 10.

Laman web tersebut menampilkan data-data hasil pembacaan sensor pada sensor node yaitu menampilkan status nilai sensor, intensitas cahaya, dan waktu terakhir data diperbarui. Ditampilkan pula tombol untuk melakukan controlling, tombol AUTO untuk pengecekan nilai sensor dan menjalankan aksi agar berjalan secara otomatis, ON untuk menyalakan

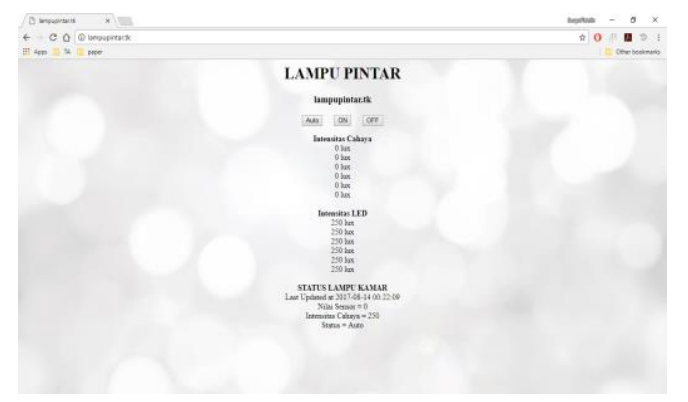

Gambar 10. Tampilan Laman Web

Tabel 4. Reliability dan Availability 1 Node

\begin{tabular}{|c|c|c|c|c|}
\hline Node & $\begin{array}{c}\text { Jumlah } \\
\text { Paket } \\
\text { Berhasil }\end{array}$ & $\begin{array}{c}\text { Jumlah Paket } \\
\text { Gagal }\end{array}$ & $\begin{array}{c}\text { Reliability } \\
(\%)\end{array}$ & $\begin{array}{c}\text { Availability } \\
(\%)\end{array}$ \\
\hline A & 499 & 1 & 99.80 & 99.80 \\
\hline
\end{tabular}

Tabel 5. Reliability dan Availability 2 Node

\begin{tabular}{|c|c|c|c|c|}
\hline Node & $\begin{array}{c}\text { Jumlah Paket } \\
\text { Berhasil }\end{array}$ & $\begin{array}{c}\text { Jumlah Paket } \\
\text { Gagal }\end{array}$ & $\begin{array}{c}\text { Reliability } \\
(\%)\end{array}$ & $\begin{array}{c}\text { Availability } \\
(\%)\end{array}$ \\
\hline A & 142 & 5 & 96,48 & 96,60 \\
\hline B & 133 & 4 & 96,99 & 97,08 \\
\hline
\end{tabular}

lampu secara langsung dan OFF untuk mematikan lampu secara langsung. Semua riwayat controlling ditampilkan juga di laman web.

\subsection{Pengujian Sistem Keseluruhan}

Pengujian dilakukan dengan menjalankan keseluruhan dan mengamati proses data yang masuk ke dalam Raspberry Pi. Data tersebut masuk melalui coodinator node kemudian dilakukan capturing dengan Minicom dan data disparsing untuk memisahkan data berdasarkan pengirimnya. Pada pengujian dilakukan percobaan dengan mengirim data dari node A saja serta dari node A dan node $\mathrm{B}$ secara bersamaan dengan perulangan 200 kali. Hasilnya diolah dengan rumus reliability dan availability. Hasil pengujian data tertera pada Tabel 4. Pada pengujian 1 sensor node diperoleh informasi 499 paket berhasil dikirim dan 1 paket gagal dikirim sehingga reliability sebesar $99,8 \%$ dan availability $99,8 \%$.

Dari hasil pengujian (Tabel 5), pada sensor node A terdapat 142 paket berhasil dikirim dan 5 paket gagal dikirim sementara sensor node $\mathrm{B}$ terdapat 133 paket berhasil dan 4 paket gagal dikirim. Paket gagal dikirim disebabkan oleh kegagalan capture pada minicom karena data dari node $\mathrm{A}$ dan node $\mathrm{B}$ dikirim secara bersamaan ke coodinator node. Berdasarkan jumlah waktu berhasil dan jumlah waktu gagal diperoleh reliability sebesar 95,17\% dan availability sebesar 95,4\%.

\section{Kesimpulan}

Setelah melakukan perancangan dan pengujian sistem, diperoleh kesimpulan sebagai berikut:

1. Lampu LED akan menyala dan berubah warna sesuai aktifitas yang terjadi di dalam suatu rumah. Lampu LED akan berwarna putih pada pukul 08.00 hingga 15.00 dengan asumsi pada rentang jam tersebut terjadi aktivitas dalam rumah. Lampu LED berubah warna menjadi kuning pada pukul 15.01 pukul 17.59 dengan asumsi pada rentang jam tersebut merupakan waktu istirahat. Selain jam tersebut lampu tetap berwarna kuning dan bisa di matikan secara manual.

2. Nilai intensitas cahaya semakin kecil maka nilai LED value juga semakin besar. Jika nilai intensitas semakin besar maka nilai LED value juga semakin kecil.

3. Sistem smart lighting dapat melakukan monitoring keadaan lampu dan sensor mulai dari intensitas cahaya ruangan dan intensitas cahaya lampu yang dikeluarkan. Sistem smart lighting juga dapat melakukan controlling sistem dengan masukan otomatis, langsung menyala dan langsung mati. Semua informasi hasil sensing dan tombol pada proses controlling dapat diakses pada laman web. 
4. Semakin jauh letak node maka nilai delay semakin besar dan nilai throughput semakin kecil.

5. Rata-rata ukuran paket untuk monitoring sebesar 26279.47 bytes sedangkan controlling 20770,6 bytes. Paket monitoring lebih besar karena membawa data-data informasi dari sensor node sedangkan controlling hanya membawa inputan.

6. Nilai throughput rata-rata pada proses monitoring sebesar 210,827 bytes/second sedangkan pada proses controlling sebesar 193,7 bytes/second. Throughput monitoring lebih besar karena ukuran paket labih besar.

7. Nilai delay rata-rata pada proses monitoring sebesar 237,69 milisecond dan controlling sebesar 1151,61 milisecond. Delay pada proses monitoring lebih kecil karena paket yang dikirimkan proses monitoring lebih kecil daripada paket proses controlling .

8. Sistem memiliki tingkat reliability sebesar 95,17\% dan availability sebesar 95,4\% yang dilihat pada Raspberry Pi.

\section{Daftar Pustaka}

[1] M. Peterson, "The Psychology of Color," [Online]. Available: http://www.moosepeterson.com/techtips/color. html. [Diakses 28 September 2016].

[2] N. Chandrakar, S. Kaul, C. S. V. Manoj Mohan dan K. Prabhu, "NFC based profiling of smart home lighting system," 2015 International Conference on Industrial Instrumentation and Control (ICIC), 2015.

[3] R. L. Nurbed, "Prototype Smart Street Lighting Di Jaringan Sensor Nirkabel,” 2015.
[4] A. Bahga dan V. Madisetti, Internet of Things: A Hands-On Approach, Georgia: VPT, 2014.

[5] "HomePlug Alliance," [Online]. Available: http://www.homeplug.org/. [Diakses 25 Oktober 2016].

[6] M. Sibarani, "IMPLEMENTASI SISTEM WIRELESS SENSOR," Universitas Indonesia, 2008.

[7] I. P. A. E. Permana dan S. Suakanto, Wireless Sensor Network, Bandung: Penerbit Informatika, 2015.

[8] D. S. Yinbiao, "Internet of Things: Wireless Sensor Network," White Paper, no. International Electrotechnical Commission, 2014.

[9] D. Ahamed, "THE ROLE OF ZIGBEE TECHNOLOGY INFUTURE DATACOMMUNICATION SYSTEM," Sathak Institute of Technology, 2005.

[10] N. Noorani, "Wireless Multi-Sensor Monitoring System Utilizing IEEE 802.15.4 Communication Standards for Water Leakage Detection," Department of Electrical and Computer Engineering.

[11] B. S. Nasional, " Tingkat pencahayaan minimum dan renderasi warna yang direkomendasikan". Indonesia Paten SNI 036575-2001, 8 Agustus 2001.

[12] E. Dahlman, C. Oestges, A. C. Bovik dan B. A. Fette, Communications Engineering Desk Reference, Oxford: Elsevier Inc., 2009.

[13] L. Hapsari, "IMPLEMENTASI DAN ANALISIS PERFORMANSI VRRP (VIRTUAL ROUTER REDUNDACY PROTOCOL) PADA JARINGAN VPLS," Universitas Telkom, 2013. 